\title{
Distribution, status and conservation of the black-and-white snub-nosed monkey Rhinopithecus bieti in Tibet
}

\author{
Zuo-Fu Xiang, Sheng Huo, Lin Wang, Liang-Wei Cui, Wen Xiao, Rui-Chang Quan and Zhong Tai
}

\begin{abstract}
The black-and-white snub-nosed monkey Rhinopithecus bieti (Colobinae), categorized as Endangered on the IUCN Red List, is endemic to the TransHimalayas (the Hengduan Mountains) of north-west Yunnan and south-east Tibet. To evaluate the species' current status in Tibet we surveyed six sites in Honglaxueshan National Nature Reserve, believed to be the area's only remaining location of $R$. bieti. Sites were identified from previous surveys and interviews with villagers and local officials. Three sub-populations, with a total of $>300$ individuals, were located in conifer and evergreen broad-leaf forests, which together comprise $971 \mathrm{~km}^{2}$. One of the sub-populations, in Zhina, is a new discovery, and is the northernmost known sub-population of $R$. bieti. Identified threats to the species include habitat destruction through wood extraction, uncontrolled grass fires, cutting of oak Quercus aquifolioides branches, inappropriate attitudes to $R$. bieti
\end{abstract}

when people carry out economic activities in the forest, and hunting. Opportunities for conservation include the existence of sacred mountains, the limited possibilities for agriculture, and the economic dependency of villagers on the forest. We recommend the development of a sustainable ecosystem to reduce pressure on $R$. biet $i$ and its forest habitat, including use of solar energy for heating and cheap electricity for cooking to minimize dependence on firewood, introduction of techniques for high crop yields to improve food supplies, and release of some farmland for planting grass, which can be used to raise livestock in enclosures and thus reduce the cutting of oak.

Keywords Black-and-white snub-nosed monkey, Hengduan Mountains, Honglaxueshan National Nature Reserve, Rhinopithecus bieti, Tibet.

\section{Introduction}

The black-and-white snub-nosed monkey Rhinopithecus bieti (Colobinae; Plate 1), categorized as Endangered on the IUCN Red List (IUCN, 2007), is endemic to the Trans-Himalayas (the Hengduan Mountains) in northwest Yunnan and south-east Tibet, China. The range of $R$. bieti lies between $26^{\circ} 14^{\prime} \mathrm{N}$ and $29^{\circ} 20^{\prime} \mathrm{N}$, and is bordered by the Mekong River to the west and the Yangtze River to the east (Long et al., 1994, 1996). This primate was first described by Milne-Edwards in 1897 (Allen, 1938)

\footnotetext{
Zuo-Fu Xiang $^{\star} \dagger$ (Corresponding author) Sheng Huo + , Lin Wang, Wen Xiao and Rui-Chang Quan Kunming Institute of Zoology, Chinese Academy of Sciences, Kunming, Yunnan, China. E-mail zorph111@yahoo.com.cn

Liang-Wei Cui South West Forestry College, Kunming, Yunnan, China.

Zhong Tai Baimaxueshan National Nature Reserve, Deqin, Yunnan, China.

${ }^{*}$ Current address: College of Life Science and Technology, Central South University of Forestry \& Technology, 498 Shaoshan Nanlu, Changsha, Hunan, 410004, China.

†Zuo-Fu Xiang and Sheng Huo contributed equally to this work.

Received 28 December 2005. Revision requested 25 April 2005.

Accepted 2 October 2006.
}

but it was believed to be extinct because no further information about its occurrence was reported following its initial discovery. The confirmation that the species is extant came in 1960 when eight skins were obtained in Deqin County (Peng et al., 1962).

Study of the species, however, is hampered by the harsh physical conditions in its natural habitat. The steep slopes and deep gorges are difficult to negotiate and some mountain paths are closed for 3-6 months of the year by heavy snow. The visibility of animals in the area's coniferous forest is low and the species is extremely shy of people because of a long history of hunting. Early surveys of distribution (Li et al., 1981; Bai et al., 1987) were therefore short-term and limited to the more accessible areas of Yunnan. The only survey that spanned a longer period and covered most of the species' range was that of Long et al. $(1994,1996)$, which showed that there were $<1,500$ individuals in 11 isolated sub-populations in north-western Yunnan and two subpopulations in south-eastern Tibet. Information about the species in Tibet came from only one study, which consisted of several short surveys in 1988 and 1991 (Long et al., 1994). The most recent research on the species (Xiao et al., 2003) did not include the Tibetan population. 


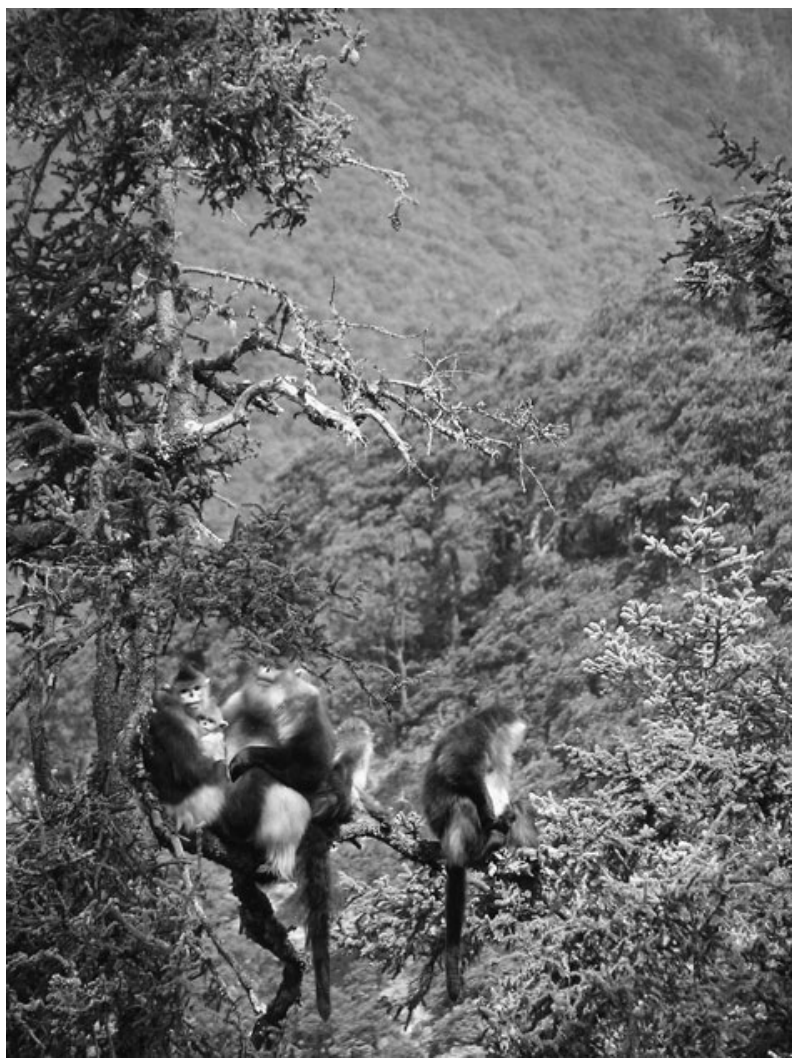

Plate 1 One male, multi-female unit of $R$. biet $i$ in the coniferous forest of Honglaxueshan National Nature Reserve, Tibet.

Here we (1) provide information on the distribution, sub-population size, and conservation status of $R$. biet $i$ in Tibet, (2) present information on the vegetation of its habitat, and (3) recommend conservation strategies for a sustainable ecosystem where both people and $R$. biet $i$ can coexist.

\section{Study area}

We carried out our study at Honglaxueshan National Nature Reserve in Mangkang County, south-east Tibet, as all reports indicated this area may be the only remaining site for $R$. biet $i$ in Tibet. The vegetation of the Reserve and the adjacent region (Bamei of Yunnan) is shown in Fig. 1. The Reserve was founded in 1993, mainly to protect $R$. bieti and its habitat, and is in the Hengduan Mountains, bounded by the Mekong River to the west and Heiqu (Gatuo) River to the east. Most of this mountain range is at altitudes $>3,500 \mathrm{~m}$. The c. 185,300 ha Reserve consists of a mosaic of conifer forest, larch forest and evergreen broad-leaf forest at 3,500-4,300 $\mathrm{m}$, and deciduous broad-leaf forest at 3,200-3,600 $\mathrm{m}$ (Xiang, 2005). There are >60 villages, 2,269 households and 12,000 people around the Reserve; mostly Tibetan and a few Naxi (Xizang Forestry Survey \& Design Institute, 2000). All villagers are Tibetan Buddhists. They depend on a subsistence economy dominated by planting qingke (highland barley) below $3,800 \mathrm{~m}$, grazing yak and sheep in alpine meadows or coniferous forest, and collection of non-timber forest products such as yangdujun (a mushroom, Morchelella esculenta), songrong (a mushroom, Tricholoma bakamatsutake), chongcao and beimu (the Chinese medicinal plants Cordyceps sinensis and Fritillaria cirrhosa, respectively) between mid May and early October (Xiang, 2005).

\section{Methods}

We carried out $>100$ interviews in $>15$ villages and made direct observations to determine the presence of $R$. bieti in the forest. Interviews were used to obtain preliminary information on $R$. bieti (zhecha in Tibetan, which means black-and-white monkeys), and on human activities in the forest, and to increase local awareness and pride regarding the importance of $R$. bieti as a unique species endemic to Tibet and Yunnan. Interviews were carried out in a brief, unstructured and informal fashion covering the following issues: (1) presentation of pictures of local primates (including two macaques, Macaca mulatta and Macaca thibetana) to ensure that interviewees could identify $R$. bieti, (2) activities carried out that could threaten $R$. bieti, (3) the historical presence of $R$. bieti, and (4) the existence of any sacred mountain (generally declared as such by a Living Buddha, a senior Tibetan Buddhist monk, and where villagers are restricted from hunting, tree felling and similar activities).

Based on these interviews we carried out detailed surveys at six sites: Zhina, Huola, Xiaochangdu, Milaka, Bajia and Salin (Fig. 1). These surveys were carried out over 347 days, with 242 days of tracking and 638 hours of observations, from November 2002 to April 2005 (Table 1). The presence or absence of ranging and foraging signs (e.g. faeces, broken branches) were used to estimate the species' range. Once the presence of $R$. bieti was confirmed at a site we tried to approach them to count group members. If this procedure was impossible the number of adult males $\left(N_{\mathrm{m}}\right)$ was used as an indication of OMUs (one male, multi-female unit; Kirkpatrick et al., 1998; Plate 1). Using $N_{\mathrm{m}}{ }^{*} N_{\mathrm{OMU}}$, we estimated the sub-population size, where $N_{\mathrm{OMU}}$ is the OMU size of the Xiaochangdu sub-population (range 9-14; Xiang, 2005). We evaluated conservation status by assessing the response of $R$. bieti to surveyors, the nearest distance that surveyors could approach the animals, and the frequency of steel snares encountered in the forest (not along trails). We also carried out surveys in the area between the presumed home ranges of two sub-populations located at Zhina and Xiaochangdu to look for indirect 


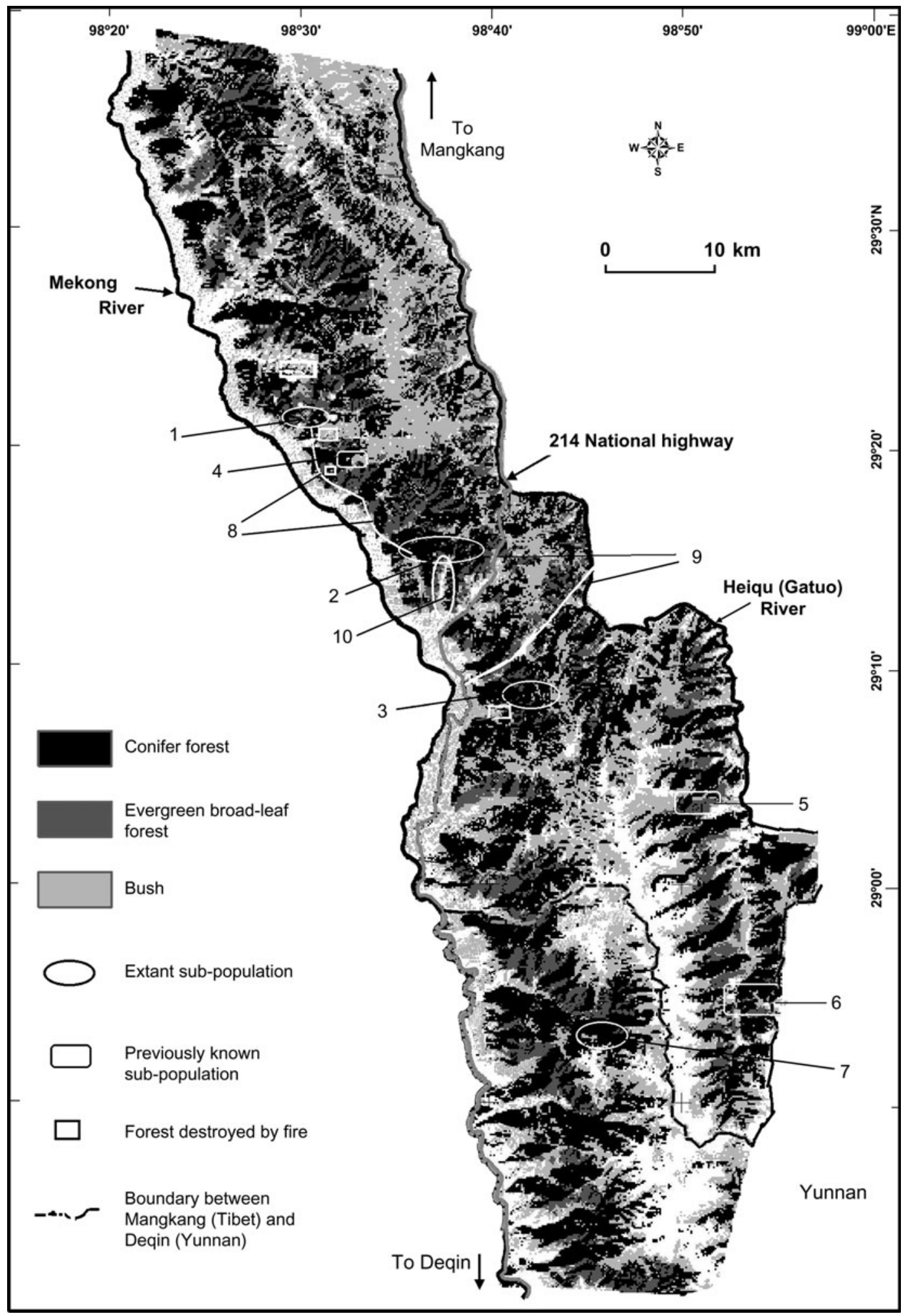

Fig. 1 Honglaxueshan National Nature Reserve, showing the current and historical occurrence of $R$. bieti sub-populations in Tibet, vegetation types, and the nearest sub-population in Yunnan (7, Bamei). Sub-populations of $R$. bieti were located in: 1, Zhina;

2, Xiaochangdu; 3, Milaka. Sites where R. bieti was historically known but where we were unable to locate the species were: 4, Huola; 5, Bajia; 6, Salin. There is a potential habitat corridor between the Zhina and Xiaochangdu sub-populations, identified by the presence of R. bieti faeces (8). There is a potential barrier (national highway 214, and Milaka village and its farmland (9)) to movement between the Tibet and Yunnan sub-populations. Sampling for the estimation of villagers' cash income (Table 4) was carried out in Bazhugong village (10). 
Table 1 Dates, total number of days, number of days spent tracking and distance walked in the forest, and number of hours of observations of R. bieti at six sites in Honglaxueshan National Nature Reserve (Fig. 1).

\begin{tabular}{|c|c|c|c|c|c|}
\hline Date & Days & $\begin{array}{l}\text { Days spent } \\
\text { tracking }\end{array}$ & $\begin{array}{l}\text { Distance } \\
\text { walked }^{1}(\mathrm{~km})\end{array}$ & $\begin{array}{l}\text { Hours of } \\
\text { observation }^{2}\end{array}$ & Site $^{3}$ \\
\hline 22-26 Nov. 2002 & 5 & 4 & 26 & 20 & Xiaochangdu ${ }^{3}$ \\
\hline 27-29 Nov. 2002 & 3 & 0 & 17 & 0 & Milaka $^{3}$ \\
\hline 16 June-15 Aug. 2003 & 61 & 60 & 283 & 168.5 & Xiaochangdu ${ }^{3}$ \\
\hline 16 June-15 Aug. 2003 & 61 & 8 & 229 & 45 & Milaka $^{4}$ \\
\hline 24 Oct.-28 Dec. 2003 & 66 & 64 & 428 & 115.25 & Xiaochangdu ${ }^{3}$ \\
\hline 2 Mar.-7 Apr. 2004 & 37 & 37 & 149 & 76.25 & Xiaochangdu ${ }^{3}$ \\
\hline 18-28 May 2004 & 11 & 11 & 51 & 39.75 & Xiaochangdu ${ }^{3}$ \\
\hline 29 May-6 June 2004 & 9 & 0 & 78 & 0 & Huola $^{3}$ \\
\hline 8-14 June 2004 & 7 & 7 & 29 & 29.75 & Xiaochangdu ${ }^{3}$ \\
\hline 15-22 June 2004 & 8 & 0 & 43 & 0 & Milaka, Bajia $^{3}$ \\
\hline 1-3 Sept. 2004 & 3 & 3 & 11 & 15.5 & Xiaochangdu ${ }^{3}$ \\
\hline 6-18 Dec. 2004 & 11 & 0 & 50 & 0 & Bajia, Salin ${ }^{5}$ \\
\hline 25 Jan.-28 Mar. 2005 & 63 & 46 & 326 & 119.75 & Xiaochangdu ${ }^{3}$ \\
\hline 4-5 Apr. 2005 & 2 & 2 & 18 & 8.25 & Zhina $^{3}$ \\
\hline Total & 347 & 242 & 1,738 & 638 & \\
\hline
\end{tabular}

${ }^{1}$ Estimated by straight line displacements on the map

${ }^{2}$ Observed with field scope or binoculars

${ }^{3}$ Survey carried out by Xiang Z.F. and field assistants

${ }^{4}$ Survey carried out by Huo S. and field assistants

${ }^{5}$ Survey carried out by Zhong T.

evidence (ranging or foraging signs) of R. bieti to verify the possible existence of a habitat corridor.

We categorized vegetation into three types: (1) conifer forest, including larch forest; (2) evergreen broad-leaf forest, including deciduous broad-leaf forest; (3) bush (rarely growing to $>2 \mathrm{~m}$ in height). Types 1 and 2 are considered to be suitable habitat for R. bieti (Xiang, 2005). Using a global positioning system we recorded the location of vegetation types in the areas surveyed. We used this information in the geographical information system ArcGIS v. 9 to overlay polygons of the three vegetation types on Landsat satellite images (resolution $30 * 30 \mathrm{~m}$ ) and calculate the total area of each vegetation type.

We evaluated threats to $R$. bieti using direct observations of human activity and interviews with local officials, guides, and the interviews with villagers, and noted the seasonal economic activities of people in the forest. The intensity of economic activities was estimated by counting the numbers of villagers passing our main study camp (at Xiaochangdu) on their way to the forest. This was done during at least 3 days per month. We investigated the cash income of local people in the Reserve by sampling the 60 households in Bazhugong village (10, Fig. 1) to estimate the forest's value to the villagers.

\section{Results}

Our surveys confirmed the existence of three subpopulations of $R$. bieti in Honglaxueshan National
Nature Reserve, with an estimated total population of $>300$ individuals (Table 2), all confined to conifer and evergreen broad-leaf forests at 3,500-4,250 $\mathrm{m}$. The areas of conifer forest, evergreen broad-leaf forest, and bush were calculated to be 712,259 and $632 \mathrm{~km}^{2}$, respectively, and therefore the area of suitable habitat for $R$. bieti is $971 \mathrm{~km}^{2}$. The sub-population at Zhina is a new discovery and is the northernmost known location of $R$. bieti. We were able to approach within 20-30 m of this subpopulation and saw four adult males in different trees. The Xiaochangdu sub-population was estimated to be 207 (32 males, 71 females, 72 juveniles and 32 infants). These counts were obtained when $R$. bieti were crossing an open area. As we probably missed some individuals during counting it is reasonable to assume that this subpopulation exceeds 210 individuals. As five adult males were observed in different trees at Milaka, the estimate sub-population size was $c$. 50. We were unable to confirm the species' presence at Huola, Bajia and Salin, where R. bieti was previously known (Zhong et al., 1998; interviews with villagers, this study).

The discovery of faeces of $R$. bieti ( $R$. bieti faeces look like abacus beads and are easy to distinguish from the droppings of other animals) in the forests between the Zhina and Xiaochangdu sub-populations suggests the area is a habitat corridor and that movement may occur between these two sub-populations (Fig. 1). The Xiaochangdu and Milaka sub-populations are separated by national highway 214, and Milaka village and its farmland (Fig. 1). 
Table 2 Details of the three sub-populations of R. bieti located in Honglaxueshan National Nature Reserve (Fig. 1), Tibet, with the distance to which the observer could approach, the estimated population size (see text for details), whether steel snares were encountered, and location in relation to a sacred mountain (see text for details).

\begin{tabular}{|c|c|c|c|c|c|c|}
\hline $\begin{array}{l}\text { Nearest village } \\
\text { (distance, } \mathrm{m} \text { ) }\end{array}$ & Location & Altitude (m) & $\begin{array}{l}\text { Distance to } \\
\text { observer (m) }\end{array}$ & $\begin{array}{l}\text { Population } \\
\text { size }\end{array}$ & $\begin{array}{l}\text { Steel snares } \\
\text { encountered }\end{array}$ & $\begin{array}{l}\text { Scared } \\
\text { mountain }\end{array}$ \\
\hline 1, Zhina $(<800)$ & $29^{\circ} 22^{\prime} \mathrm{N}, 98^{\circ} 28^{\prime} \mathrm{E}$ & $3,700-4,200$ & $20-30$ & c. 50 & Never & Near \\
\hline 2, Xiaochangdu (200) & $29^{\circ} 15^{\prime} \mathrm{N}, 98^{\circ} 37^{\prime} \mathrm{E}$ & $3,500-4,250$ & $<20$ & $>210$ & Never & Within \\
\hline 3, Milaka $(>2,000)$ & $29^{\circ} 08^{\prime} \mathrm{N}, 98^{\circ} 41^{\prime} \mathrm{E}$ & $3,700-4,250$ & $>100$ & c. 50 & Almost every day & Far away \\
\hline
\end{tabular}

Based on our observations and on the interviews we identified the threats to $R$. bieti as (1) habitat destruction through wood extraction, uncontrolled grass fires, and cutting of oak Quercus aquifolioides branches, (2) inappropriate behaviour, such as shouting at and chasing $R$. bieti, by people carrying out economic activities in the forest, and (3) hunting. Extracted wood is mainly used for building houses, fencing farmland, and firewood. With increasing economic development in the area people are beginning to build larger houses and this requires more wood. The villagers also use wood to build fences around farmland to prevent destruction of crops by livestock. Firewood for cooking and heating traditionally comes from both live and dead wood in the forest. Because the climate is cold (the annual average temperature at $3,800 \mathrm{~m}$ is $4.7^{\circ} \mathrm{C}$; Xiang, 2005) most firewood is used for heating. Throughout the region firewood is the main energy source, although electricity is an alternative and is preferred when family income permits. Controlled grass fires to clear pasture and encourage growth of new grass for yak and sheep are common in the Reserve. Controlled grass fires occur primarily from April to May, and occasionally get out of control. During our surveys we saw at least four large areas of conifer forest that were destroyed by fire (Fig. 1). Villagers cut oak branches for their leaves to raise livestock in winter. Sometimes, they cut down a whole oak tree for only its branches and leaves. Cutting for both branches/leaves and firewood occurs mostly at the edge of the forest and causes the forest edge to retreat.

Economic activities and variations in their intensity are shown in Table 3. More than 100 people per day were recorded entering the forest for songrong collection, which can fetch as much as USD 20-30 per $\mathrm{kg}$ when fresh and comprises $64 \%$ of total cash income per household (Table 4). These activities do not pose a threat to the species but serious disturbance is caused when villagers shout at or chase $R$. bieti for amusement. Such behaviour could induce females to abandon their infants; this has apparently happened in the Xiaochangdu sub-population. As we regularly encountered steel snares within the range of the Milaka sub-population we believe hunting is still common, although steel snares are mainly used to catch deer Moschus fuscus or other mammals.

Based on our observations and interviews, major opportunities for the conservation of $R$. bieti include: (1) the existence of sacred mountains, (2) the limited possibilities for agriculture and hence land clearance, (3) the value of the forests to the villagers. Every village has its own sacred mountain where it is taboo to kill any living beings; such mountains become refuges for wildlife. Tibetans in the area usually build their farmhouses beside the forest and herd livestock in the forest or on alpine meadows above the tree line. Analysis of the cash income of 60 households indicated that villagers mainly

Table 3 Annual human economic activities and intensity in the habitat of R. bieti at Xiaochangdu (Fig. 1).

\begin{tabular}{lllr}
\hline Period & Human activity & Forest type & Altitude (m) \\
\hline Jan.-Apr. & Stock grazing & Conifer forest & $3,800-4,000$ \\
May-June & Stock grazing & All forests & $3,800-4,500$ \\
& Morchelella esculenta collection & Deciduous broad-leaf forest & $3,500-3,900$ \\
& Cordyceps sinensis collection & Larch forest & $4,000-4,400$ \\
July & Stock grazing & All forests & $3,800-4,500$ \\
& Fritillaria cirrhosa collection & All forests \& bush & $4,200-4,500$ \\
Aug.-Sept. & Auricularia auricular collection & All forests \& bush & $4,200-4,500$ \\
& Stock grazing & All forests & $3,800-4,500$ \\
Oct.-Dec. & Tricholoma bakamatsutake collection & Evergreen broad-leaf forest & $3,800-4,250$ \\
& Stock grazing & All forests & $3,800-4,200$ \\
& Picking oak fruit & Evergreen broad-leaf forest & $3,800-4,300$ \\
\hline
\end{tabular}

*Number of people going to the forest by way of a path that crosses the study camp 
Table 4 Cash income per household (converted to USD) from stock raising and non-timber forest product (NTFP) collection, assessed from a sample of 60 households in Bazhugong village (Fig. 1) in 2003.

\begin{tabular}{lcc}
\hline & $\begin{array}{c}\text { USD per } \\
\text { household }\end{array}$ & $\begin{array}{l}\text { \% of non- } \\
\text { agriculture } \\
\text { activity }\end{array}$ \\
Activity & 169 & 20.0 \\
\hline Stock raising & & \\
NTFP collection (local name, & & \\
$\quad$ Latin name) & 544 & 64.3 \\
Songrong (Tricholoma bakamatsutake) & 57 & 6.7 \\
Yangdujun (Morchelella esculenta) & 66 & 7.8 \\
Beimu (Fritillaria cirrhosa) & 10 & 1.2 \\
Chongcao (Cordyceps sinensis) & 846 & 100 \\
Total & & \\
\hline
\end{tabular}

depend on non-timber forest products, which comprise $80 \%$ of total cash income (Table 4 ), and partly on raising livestock.

\section{Discussion}

Taken together with the most recent surveys in Yunnan (Xiao et al., 2003; Xiao, 2004) the global population of $R$. bieti is $c .1,500$ in 14 sub-populations. This is less than reported by Long et al. (1994), but more than reported by Long et al. (1996). This does not mean the global population is stable because in Yunnan some new subpopulations have been located and some extirpated (Xiao et al., 2003). The only stable sub-population appears to be that of Xiaochangdu in Honglaxueshan National Nature Reserve in Tibet, which is approximately the same size as in the last survey, in 1988 (Long et al., 1994). Because of the absence of snares in Xiaochangdu and Zhina, probably because they are within and near a sacred mountain, respectively, $R$. biet $i$ is probably more secure in these areas than in Milaka. The sub-population in Milaka may be genetically isolated from the other sub-populations.

Together with Yunnan (Xiao et al., 2003) the area of suitable habitat for $R$. bieti is $c .5,040 \mathrm{~km}^{2}$. It could be feasible to create a habitat corridor between the subpopulations at Milaka in Tibet and Bamei in Yunnan by reforestation. However, because the two localities belong to different administrative regions, the implementation of such a plan would be complicated. The most feasible method of implementation would be for NGOs to initiate compatible projects in Tibet and Yunnan.

Villagers did not see any $R$. bieti at Huola after extensive destruction by an uncontrolled grass fire in 1976. Although Long et al. (1994) reported R. bieti in Bajia we could not locate them. The Bajia sub-population is probably the same group as at Milaka because the forest between the two localities is continuous. We were unable to locate the sub-population at Salin reported by Zhong et al. (1998). We speculate that $R$. bieti may have been extirpated in this area, which is neither in nor near a sacred mountain, as a result of intensive poaching because hunting is not forbidden. The bones of $R$. biet $i$ are used as a traditional medicine for treating rheumatism and their fur for making clothes, and hunting is common within the species' range (Bai, 1987). Habitat destruction is also a major threat to $R$. bieti (Zhao, 1988), with wood extraction, uncontrolled grass fires, and cutting of oak branches occurring in the area. Slashand-burn agriculture or shifting cultivation is commonly used by people living in other regions where primates occur (e.g. China: Zhao, 1996; Xiang et al., 2004; Madagascar: Vargas et al., 2002) but does not occur in Honglaxueshan National Nature Reserve because the success of qingke cultivation is low above $3,800 \mathrm{~m}$. Because the main range of $R$. bieti in the Reserve is above $3,800 \mathrm{~m}$ (Xiang, 2005) agriculture is not a threat to the species.

Based on our results and analysis we make the following management recommendations for the conservation of $R$. bieti:

(1) The Administrative Bureau of the Reserve needs to control the illegal poaching in Milaka by increased patrolling and law enforcement and by requesting that the Living Buddha declare the range of the Milaka subpopulation a sacred mountain, launch reforestation programmes at sites destroyed by fire, encourage use of wire instead of wood as building material for fences, improve control of fires, carry out an education programme to ensure that villagers do not shout at or chase $R$. bieti when undertaking economic activities in the forest, and carry out a community co-management programme with the help of NGOs, as already occurs in Baimaxueshan Nature Reserve in Yunnan.

(2) Foster Buddhist tradition and enlarge its effect on the people of the Reserve. This may be achieved by helping the influential Honglaxueshan Buddhist School. However, this non-government school, which is for teaching Tibetan Buddhists, has only a small budget, acquired from the donation of a senior Living Buddha and students' tuition fees.

(3) International NGOs could extend their conservation programme for this species to all areas of its distribution, including Tibet, and use $R$. bieti as a catalyst for regional biodiversity conservation. These programmes could be implemented as support for the ongoing Project for Protecting Natural Forest and Returning Field to Forest/Grassland, which was launched by the Chinese government in 1998. Such programmes could include capacity building for the Reserve, education activities, and research actions. 
(4) For the long-term conservation of this species management actions are required that develop a sustainable ecosystem. To reduce the collection of firewood and enforce better habitat protection, we propose several activities that may lower anthropogenic pressure on the ecosystem: (1) use solar energy to boil water and heat houses, especially in winter, as well as building smallscale hydro-power stations on streams and offering cheap electricity for cooking, (2) introduce techniques for high yields of crops to provide food for villagers, and release farmland for planting grass and use this to raise livestock in enclosures, thus reducing the cutting of oak branches.

We have communicated our recommendations to the Administrative Bureau of the Reserve, who have now built wire fences along the highway and in some villages. In addition, international NGOs have an interest in the conservation of $R$. bieti: The Nature Conservancy formulated a conservation plan for the area in 2005, and Conservation International has approved a plan to work with the Honglaxueshan Buddhist School.

\section{Acknowledgments}

This study was supported by the National Natural Science Foundation of China (30630016, 30470310), the Chinese Academy of Sciences (KSCX2-1-03), and Central South University of Forestry \& Technology. We thank the Administrative Bureau of Honglaxueshan National Nature Reserve of Mangkang County in Tibet for their support, Dingzen, Ciren, Dengpei and A'nan for their assistance as Tibetan translators, Professor Zhao Q.-K. for suggestions on presentation of the figure and tables, C.-C. Grueter for help with English, and two anonymous reviewers for their invaluable suggestions.

\section{References}

Allen, G.M. (1938) The Mammals of China and Mongolia (Part I). American Museum of Natural History, New York, USA.

Bai, S.C. (1987) Survey on hunting of Yunnan golden monkeys. Sichuan Animals, 1, 13-15.

Bai, S.C., Zou, S.Q., Lin, S., Tuo, D., Tu, Z. \& Zhong, T. (1987) Preliminary observation of distribution, number and population structure of Rhinopithecus bieti in Baima Xueshan National Reserve, Yunnan, China. Zoological Research, 8, 413-419. [in Chinese with an English abstract]

IUCN (2007) 2007 IUCN Red List of Threatened Species. IUCN, Gland, Switzerland [http://www.iucnredlist.org, accessed 22 September 2007]

Kirkpatrick, R.C., Long, Y.C., Zhong, T. \& Xiao, L. (1998) Social organization and range use in the Yunnan snub-nosed monkey Rhinopithecus bieti. International Journal of Primatology, 19, 13-51.

Li, Z.X., Ma, S.L., Hu, C.H. \& Wang, Y.X. (1981) The distribution and habit of Yunnan snub-nosed monkey. Zoological Research, 2, 9-16. [in Chinese with an English abstract]
Long, Y.C., Kirkpatrick, R.C., Zhong, T. \& Xiao, L. (1994) Report on the distribution, population, and ecology of the Yunnan snub-nosed monkey (Rhinopithecus bieti). Primates, 35, 241-250.

Long, Y.C., Kirkpatrick, R.C., Zhong, T. \& Xiao, L. (1996) Status and conservation of the Yunnan snub-nosed monkey. Chinese Biodiversity, 4, 145-152. [in Chinese with an English abstract]

Peng, H.S., Gao, Y.T., Liu, C.K., Feng, Z.J. \& Chen, Q.X. (1962) Report on mammals from south-west Scechwan and northwest Yunnan. Acta Zoologica Sinica, 14, 105-129. [in Chinese with an English abstract]

Vargas, A., Jiméneza, J., Palomates, F. \& Palacios, M.J. (2002) Distribution, status and conservation needs of the goldencrowned sifaka (Propithecus tattaersalli). Biological Conservation, 108, 325-334.

Xiang, Z.F. (2005) The ecology and behavior of black-and-white snubnosed monkeys (Rhinopithecus bieti, Colobinae) at Xiaochangdu in Honglaxueshan National Natural Reserve, Tibet, China. PhD thesis, Chinese Academy of Science, Kunming, China. [in Chinese with an English abstract]

Xiang, Z.F., Huo, S., Ma, X.F. \& Ma, S.L. (2004) Status and threat factors of non-human primates at Mt Huanglian area, Yunnan, China. Chinese Journal of Ecology, 23, 168-171. [in Chinese with an English abstract]

Xiao, W. (2004) Population status of Rhinopithecus bieti and its decline in Yunnan. PhD thesis, Chinese Academy of Science, Kunming, China. [in Chinese with an English abstract]

Xiao, W., Ding, W., Cui, L.W., Zhou, R.L. \& Zhao, Q.K. (2003) Habitat degradation of Rhinopithecus bieti in Yunnan, China. International Journal of Primatology, 24, 389-398.

Xizang Forestry Survey \& Design Institute (2000) Comprehensive Programme for Honglaxueshan National Reserve of Makong County. Xizang Forestry Survey and Planning Institute, Lhasa, Tibet. [in Chinese]

Zhao, Q.K. (1988) Status of the Yunnan snub-nosed monkey. Primate Conservation, 9, 131-134.

Zhao, Q.K. (1996) Ecological information on statistics of human population and agriculture in Hengduan Mountains from Yunnan. Chinese Biodiversity, 4, 217-221.

Zhong, T., Xiao, L., Kirkpatrick, R.C. \& Long, Y.C. (1998) A brief report on Yunnan snub-nosed monkeys Rhinopithecus bieti at Bamei in northern Yunnan Provinces, China. Primate Conservation, 18, 76-80.

\section{Biographical sketches}

Zuo-Fu Xiang is interested in behavioural ecology and conservation biology. He is now conducting research on the Guizhou snub-nosed monkey Rhinopithecus brelichi on Mt Fanjing, and is also interested in other primates, including Tibetan macaques and rhesus monkeys in central China, and in the ecology of resident and migratory water birds at Dongting Lake in Hunan. Sheng Huo is now also conducting research on Phayre's leaf monkey Presbytis phayrei on Mt Gaoligong, Yunnan. Lin Wang is interested in geographical information systems and remote sensing analyses of habitat degradation. Liang-Wei Cui, Wen Xiao and Rui-Chang Quan are interested in the behavioural ecology and conservation of the black-and-white snubnosed monkey. Zhong Tai has research interests in communitybased conservation. 